\title{
Liver developed entirely outside the abdominal cavity in adult omphalocele
}

\author{
Dharmesh Jayantkumar Balsarkar
}

Published online: 30 May 2014

(C) Indian Society of Gastroenterology 2014

An omphalocele is a congenital defect that affects the development of the abdominal wall in the umbilical region with a hernia sac of variable size. It has an incidence of between $1 / 3,000$ and 1/10,000 live births [1]. It is treated surgically at birth, either as emergency or a planned procedure. The type of treatment depends on the size of the omphalocele and the general condition of the patient. It varies from single-stage procedure to a multistage procedure [1]. The finding of an untreated omphalocele in adulthood with liver totally grown outside the abdominal cavity is extremely rare with only one report so far. This 18 -year-old girl had more than three fourths of the liver grown normally outside the abdominal wall within the omphalocele sac (Fig. 1). The abdominal wall defect was closed over a dual mesh
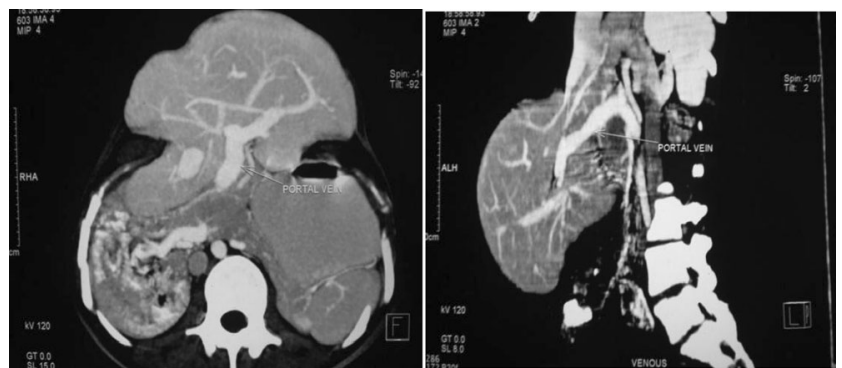

Fig. 1 Preoperative CT scan showing almost the entire liver having grown outside of the abdominal wall
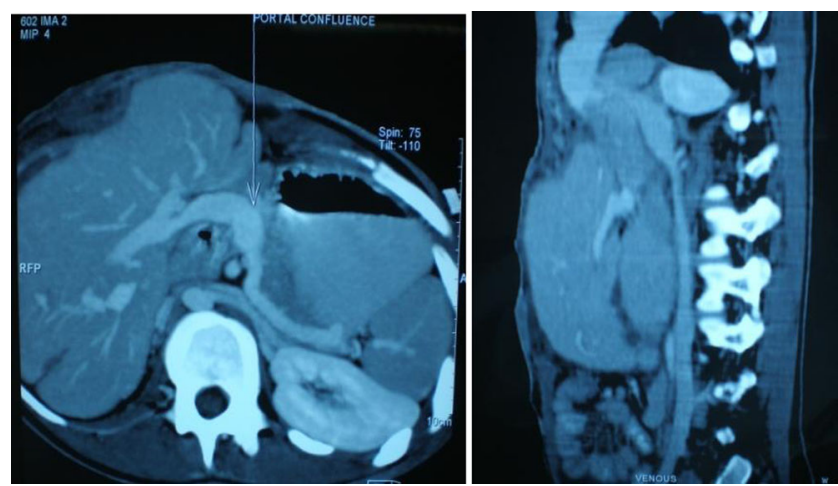

Fig. 2 Postoperative CT scan showing the liver completely in the abdominal cavity

after proper intra-abdominal placement of the liver (Fig. 2). Reconstruction, using fascia and muscles along with polypropylene mesh and with approximation of skin flaps in the midline, can be done for small defects. Tissue expansion technique can be used to achieve continuity of the skin cover [1].

\section{References}

1. D'Andrea F, Brongo S, Grella E, Grella R, Nicoletti GF. Hepatic omphalocele in an adult. Scand J Plast Reconstr Surg Hand Surg. 2004;38:236-9.
D. J. Balsarkar $(\bowtie)$

Department of General Surgery, B Y L Nair Charitable Hospital and T N Medical College, Mumbai Central, Mumbai 400 008, India e-mail: djbalsarkar@yahoo.com 